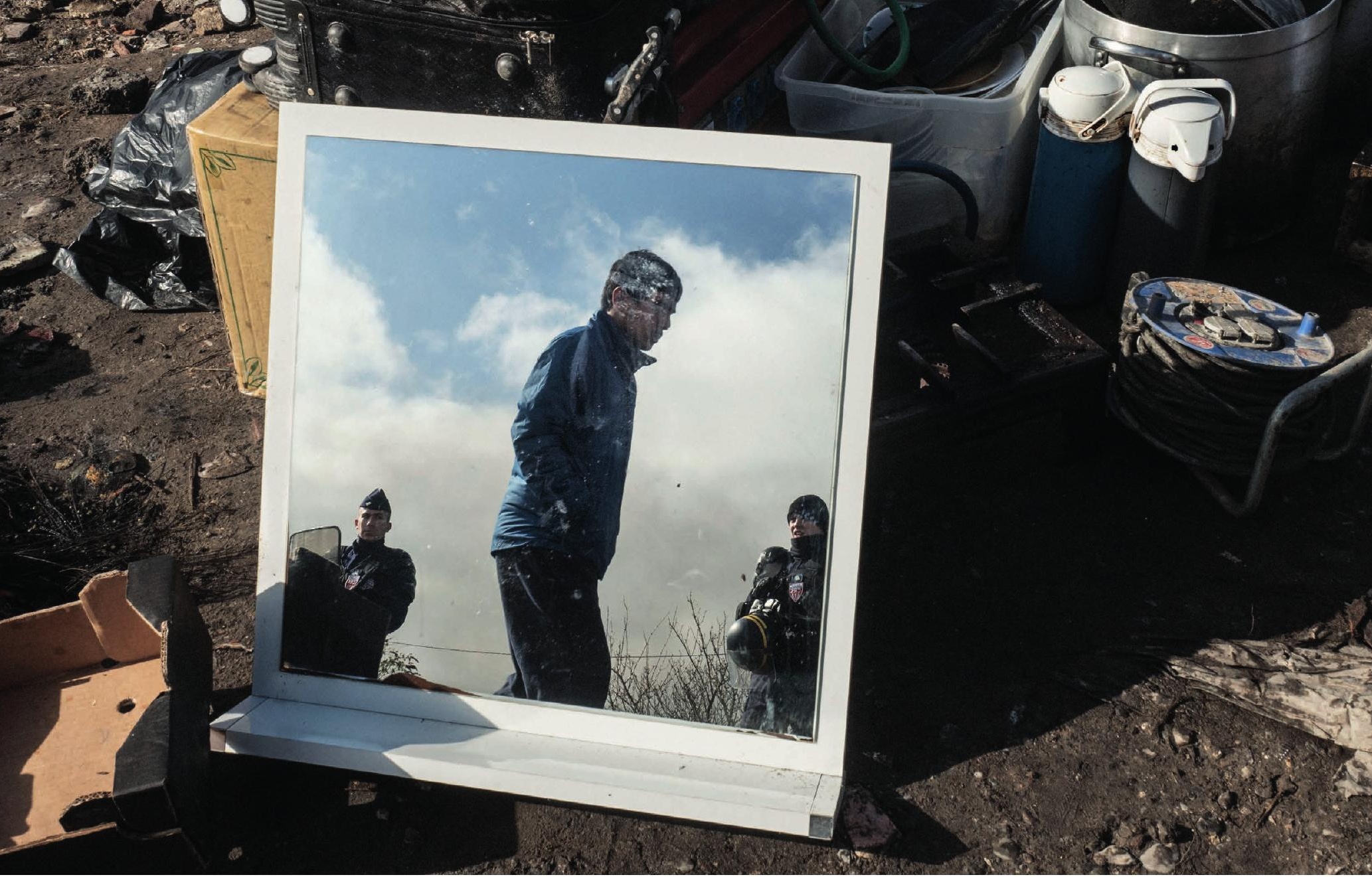

\title{
The troubled
}

\section{minds of migrants}

\section{THE REFUGEES AND MIGRANTS SURGING INTO EUROPE ARE SUFFERING VERY HIGH LEVELS OF PSYCHIATRIC DISORDERS. RESEARCHERS ARE STRUGGLING TO HELP.}

\author{
By Alison Abbott
}

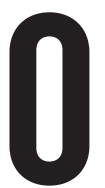

$\mathrm{n}$ an ice-cold day in January, clinical psychologist Emily Holmes picked up a stack of empty diaries and went down to Stockholm's central train station in search of refugees. She didn't have to look hard. Crowds of lost-looking young people were milling around the concourse, in clothes too flimsy for the freezing air. "It struck me hard to see how thin some of the young men were," she says.

Holmes, who works at Stockholm's Karolinska Institute, was seeking help with her research - a pilot project on post-traumatic stress disorder (PTSD), which is all too common in refugees. She wanted to see whether they would be willing to spend a week noting down any flashbacks - fragmented memories of a trauma that rush unbidden into the mind and torment those with PTSD. She easily found volunteers. And when they returned the diaries, Holmes was shocked to see that they reported an average of two a day - many more than the PTSD sufferers she routinely dealt with. "My heart went out to them," she says. "They managed to travel thousands of kilometres to find their way to safety with this level of symptoms."

Europe is experiencing the largest movement of people since the Second World War. Last year, more than 1.2 million people applied for asylum in the European Union - and those numbers underestimate the scale of the problem. Germany, which has taken in the lion's share of people, reckons that it received more than a million refugees in 2015, tens of thousands of whom have yet to officially apply for asylum. Most came from Syria, Afghanistan and Iraq. Many have experienced war, shock, upheaval and terrible journeys, and they often have poor physical health. The crisis has attracted global attention and sparked political tension as countries struggle to accommodate and integrate the influx.

What hasn't been widely discussed is the enormous burden of mental-health disorders in migrants and refugees. Clinical psychologist Thomas Elbert from the University of Konstanz in Germany is 

country causes many refugees great stress.
Arrival in a foreign, hostile

conducting a local survey of refugees that suggests "more than half of those who arrived in Germany in the last few years show signs of mental disorder, and a quarter of them have a PTSD, anxiety or depression that won't get better without help". Previous research shows that refugees and migrants are also at a slightly increased risk of developing schizophrenia.

"It is a public-health tragedy - and it's a scandal that it is not recognized as such, as a physical epidemic would be," says epidemiologist James Kirkbride of University College London.

Doctors and researchers are starting to take action. Holmes and other psychologists and psychiatrists are working with refugees to develop practical, cheap and effective therapies for trauma-related disorders - therapies that could be quickly deployed on this group. Other scientists want to work with local refugees to understand more about how the different types of stresses they suffer play out in their brains, and to learn more about the basic biology of psychiatric disorders.

Scientists hope that their studies will help them to deal with other displaced populations, and help policymakers to accommodate the current influx. Politicians have been too slow to consider mental health when they call for refugees to integrate quickly, Elbert says. "It is illusory to think that people can learn a new language and find work when they can't function properly mentally. If we want quick integration, we need an immediate plan for mental health."

\section{MAKING A NEW LIFE}

Amira is a clinical psychologist and a refugee from Syria. When the war there started, she worked in camps for Syrian refugees in Jordan. She saw people who had been physically attacked, women who had been raped and children who had been neglected. The symptoms of PTSD were clear, and she knows that many refugees have depression and anxiety, too. She asked that her real name not be used.

She arrived in Sweden at the end of December 2015, and wanted to help other refugees but was not allowed to work at first. She tried to make contacts in Stockholm and joined a language course for refugees; she felt very alone but carried on. Now, she has a 6-month position. "I met many children who have experienced war," she says. "We feel sad, [about] how our children think and how they feel. I have a child and I try to protect him."

Researchers already have a wealth of evidence about the mental health of migrant and refugee populations around the world. (The United Nations defines refugees as people fleeing armed conflict or persecution and migrants as people who choose to move to improve their lives. Asylum seekers are those seeking official refugee status; but sometimes different definitions are used.) A 2005 meta-analysis of studies performed mostly in northern Europe showed that first- and secondgeneration migrants were at much greater risk of schizophrenia than non-migrants - and that those from developing countries were more at risk than those from developed ones ${ }^{1}$.

A large cohort study published in March looked at 1.3 million people who had arrived in Sweden before 2011 (see 'Migrant crisis'). Refugees had a threefold higher incidence of schizophrenia and other psychotic disorders than native-born Swedes, and a 66\% higher incidence than migrants who were not refugees ${ }^{2}$. (The overall risk for refugees and migrants still remains comparatively low, at perhaps 2-3\%.) Kirkbride, an author on the study, says that his team's more recent analysis of UK migration data suggests that the level of increased risk of psychotic disorders may depend on how old people were when they migrated - with children potentially at greater risk.

Those who stand out most seem to be particularly vulnerable. The 2005 meta-analysis showed that black migrants in a mostly white population had an almost fivefold increased risk of psychotic disorders ${ }^{1}$. And the risk is higher for migrants living in neighbourhoods with a low proportion of residents from their own ethnic group compared with those surrounded by many of their own ethnicity ${ }^{3}$.

Psychiatrist Andreas Meyer-Lindenberg from the Central Institute for Mental Health in Mannheim, Germany, is one of those trying to understand the brain mechanisms involved. He has already studied other populations with an above-average risk of psychosis, such as city dwellers $^{4}$ and ethnic minorities ${ }^{5}$. The work suggested that the brains of these people are overly sensitive to social stress, such as a stream of disapproving feedback.

Thanks to a grant awarded last month from the state government of Baden-Württemberg, Meyer-Lindenberg plans to extend his studies by recruiting 200 refugees and 200 people from the local community. The refugees will use smartphones to note their state of mind - such as feelings of suspiciousness - and they will later receive brain scans. The eventual aim is to find patterns in the data that indicate people with abnormal processing of social stress, who may therefore be at increased risk of mental illness. Jean-Paul Selten, a psychiatrist at Maastricht University in the Netherlands, is also exploring the poisonous nature of social stress. He proposes that pressures such as social exclusion raise the risk of psychosis by changing the brain's sensitivity to the neurotransmitter dopamine ${ }^{6}$

Germany's integration plans, consolidated in a law that came into force in August, involve distributing refugees across the country to avoid the creation of large, isolated ethnic communities. That could be problematic if it increases people's isolation, but Meyer-Lindenberg says it's "actually a good policy" - because other people in the community get to know refugees, and this usually reduces xenophobia, another major source of social stress.

\section{"IT IS A PUBLIC-HEALTH TRAGEDY - AND IT'S A SCANDAL THAT IT IS NOT RECOGNIZED AS SUCH."}

Politicians consider integration to be essential for security, among other things. A handful of terrorist attacks in Europe over the past two years have been carried out by refugees or others with a migrant background who had been known to have a history of psychiatric problems. But doctors and researchers are extremely wary about making a link between refugees or migrants and terrorist acts, pointing out that very few of those with mental-health problems become violent, regardless of their origins. The security concern simply accentuates the need to help all those with mental-health problems across the population, they say.

\section{THE STRESS OF UPHEAVAL}

Psychologists recognize three windows of extreme stress for refugees: the often violent traumas in their home countries that led to their flight; the journey itself; and the arrival, when people are thrust into a foreign country. "The latter 'post-migration' phase is becoming increasingly important," says psychiatrist Malek Bajbouj from the Charité university hospital in Berlin. "Suddenly they realize they have lost everything, have no control over aspects of their lives and no social standing."

In February, Bajbouj - who is of Syrian descent and speaks Arabic - and two colleagues from other departments opened a clearing centre for refugees with mental-health problems, the first of its kind in Germany. It's a quiet building, a former hospital in the centre of Berlin - but already 1,500 troubled people have passed through its doors. "Refugees may arrive in Germany with great hope, but then find themselves stuck for months in camps with no apparent prospects," he says. "When we ask them what their greatest stressors are, they typically refer not to their traumatic memories, but to their current frustrations."

The biggest challenge for Bajbouj and others is the sheer volume of people in need of help. They must be assisted quickly and cheaply, in ways that take the pressure off overstretched health professionals. At the clearing centre, three psychiatrists assess visitors rapidly, categorizing them into those who require low-level or more-intensive psychiatric help and those who can be aided by social workers. A lot of effort goes into teaching about stress management and the science behind mental health. "Some people from rural areas hold the Djinn responsible 


\section{Migrant crisis}

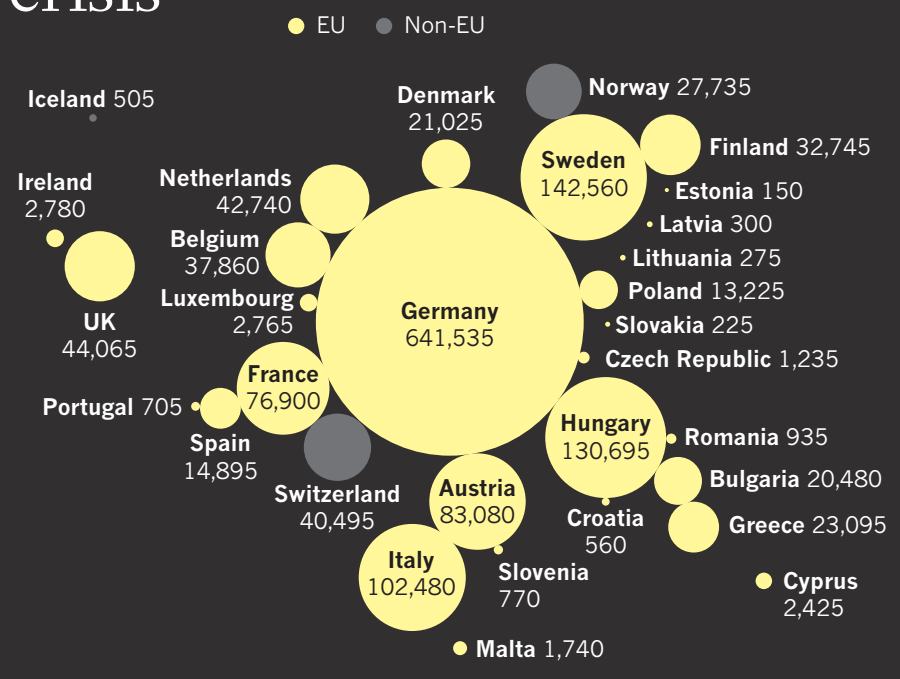

TRAUMA

Many refugees in Germany have experienced traumatic incidents: around half suffer from mental illnesses such as post-traumatic stres disorder or depression.

- Adults

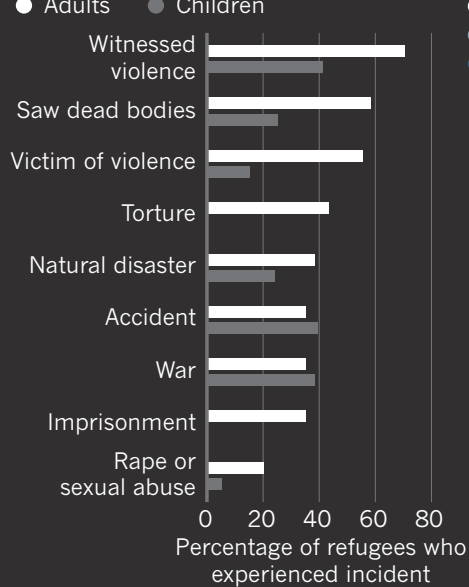

\section{PSYCHOSES}

A study of 1.3 million people in Sweden ${ }^{2}$ showed that migrants and refugees have a higher incidence of schizophrenia and other non-affective psychotic disorders.

- Swedish born

Non-refugee migrant

Refugee migrant

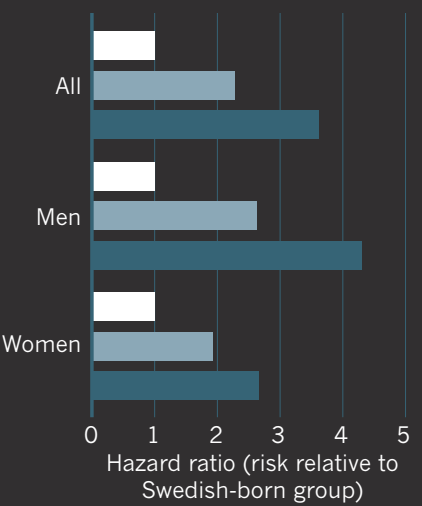

for their moods," says Bajbouj, "and we teach them that symptoms like sleeplessness and depression are biologically based and can be treated."

Elbert wants to see similar triage systems put in place across Germany. In a paper to be published next month, he and a group of colleagues call for a three-tiered approach. Refugees would initially be helped by bilingual laypeople - ideally migrants or refugees themselves - who are trained to guide people through the German health system (tier one) or to offer trauma counselling (tier two). Those in most need would progress to tier three: qualified psychologists or psychiatrists.

\section{PEACE OF MIND}

Training laypeople seems to work in emergency situations. Elbert, together with Sarah Ayoughi, a clinical psychologist from the psychosocial-care organization Ipso, carried out a randomized controlled study of people with mental-health conditions in north Afghanistan who received psychosocial counselling - a type of talking therapy - conducted by local physicians who had no previous education in psychology or psychiatry, but who were specially trained for the trial. Just 5-8 sessions improved symptoms of depression and anxiety for up to 3 months ${ }^{7}$.

And several studies, including a 2011 randomized controlled trial of former child soldiers in northern Uganda ${ }^{8}$, show that an approach called narration exposure therapy (NET), carried out by trained lay counsellors, can reduce the severity of PTSD symptoms. Elbert started developing NET with his wife Maggie Schauer, also a clinical psychologist at the University of Konstanz, when they were working with refugees in Kosovo in the late 1990s. It exploits new understanding of how memories are linked with fear circuitry in the brain. A traumatized person works with a therapist or counsellor to construct a narrative of their lives and anchor their traumatic experiences in the correct time and place.

Pragmatic as the three-tiered approach may sound, it won't be simple to introduce in Germany. Professional associations are resistant to allowing people without formal qualifications to help out with psychotherapies, and various regulations could get in the way.

But while the federal government ponders what to do, some programmes are starting up with regional government support. Schauer has received $€ 100,000$ (US $\$ 112,000$ ) to test whether NET works as well on refugees in Germany as it has in war-torn countries. And Ayoughi is organizing the training of refugees in Erfurt in Germany, with additional support from the Google Foundation.

Bajbouj thinks that the political desire to get refugees into the workforce fast may end up easing the way for more relaxed rules about psychotherapy. And there is another way to deliver inexpensive mental-health care: through the Internet and apps. He is developing an
Arabic-language version of the smartphone app PTSD Coach, which provides education, a personalized emergency plan, self-assessment and 25 different techniques to regulate stress. He is testing it in the Arab Outpatient Centre he opened at the Charité in 2008.

In Stockholm, Holmes also hopes that technology can help. The aim of her work is to test whether it's possible to subdue PTSD-linked emotional flashbacks if a person immediately plays a video game on their phone that competes for cognitive space in the brain - a technique that she has seen work in laboratory tests" "The important thing now is to develop simple new approaches to therapy that can be scaled up, and to prove that they help," she says.

Sweden, which has taken in a relatively large number of refugees, is also starting mental-health programmes. Early this year, local authorities rolled out a plan to make it easier for refugees to access support: health checks will include more questions about states of mind, and those recognized as being in need will be channelled towards psychological or psychiatric support.

The flow of refugees and migrants has eased this year, in part because Turkey has agreed to take back those who illegally entered EU countries from there. But people keep coming. This August, more than 18,000 refugees entered Germany to seek asylum. And even if the current crisis eases, conflict, poverty, natural catastrophe and climate change will inevitably drive fresh waves of migration around the world. "We've learnt lessons about mental health from crises in war-torn countries," says Ayoughi, "and we can apply these in the refugee crisis in Europe now if we get the support." Then, perhaps, lessons learnt in Europe could feed back to war zones.

Bajbouj has been calling for a 'migration think-tank', a permanent institution in Germany where scientists of different disciplines can come together to work out what needs to be done. "The challenges are not just about mental health, but about education, integration into the work force and much more," he says. "But mental health impacts everything."

\section{Alison Abbott is Nature's senior European correspondent.}

1. Cantor-Graae, E. \& Selten, J.-P. Am J. Psychiatry 162, 12-24 (2005)

2. Hollander, A.-C. et al. Br. Med. J. 352, i1030 (2016).

3. Kirkbride, J. B., Jones, P. B., Ullrich, S. \& Coid, J. W. Schizophr. Bull. 40, 169-180 (2014).

4. Lederbogen, F. et al. Nature 474, 498-501 (2011)

5. Akdeniz, C. et al. JAMA Psychiatry 71, 672-680 (2014).

6. Selten, J.-P., van der Ven, E., Rutten, B. P. F. \& Cantor-Graae, E. Schizophr. Bull. 39, 1180-1186 (2013).

7. Ayoughi, S., Missmahl, I., Weierstall, R. \& Elbert, T. BMC Psychiatry 12, 14 (2012). 8. Ertl, V., Pfeiffer, A., Schauer, E., Elbert, T. \& Neuner, F. JAMA 306, 503-512 (2011) 9. James, E. L. et al. Psychol. Sci. 26, 1201-1215 (2015). 


\section{CLARIFICATION}

The News Feature 'The troubled minds of migrants' (Nature 538, 158-160; 2016)

stated that the Berlin-based clearing centre was opened by psychiatrist Malek Bajbouj of the Charité university hospital. The centre is actually run jointly by his and two other psychiatric departments of the hospital. 